\title{
https://doi.org/10.46344/JBINO.2021.v10i02.08
}

\section{STUDY OF ANATOMICAL ASPECTS KUKUNDARA MARMA- A REVIEW ARTICLE}

\author{
Dr. Atul D Birla \\ M.D (Rachana Sharir) Associate Professor, Reader, Yashwantrao Chavan Ayurvedic Medical College \& Hospital Aurangabad ( \\ Maharashtra )
}

\section{ABSTRACT}

Marma sharir is a science of vital anatomical sites which have been established to help the practice of surgery in Ayurveda. Marma are the conglomeration of mamsa, sira, snayu, asthi and sandhi. They are the seats of parana and any injury to themleads tomajor complications, severe pain or death. Acharya Sushruta has classifed these marmas according to the shadang distribution for the purpose of easy understanding their locations, like sakthi gata (limbs), vaksha (thoracic), udar (abdominal), prishtha gata (back) and urdhava jatru gata (above the clavicular level). Most of the Kukundar Marma Aghatjanya Lakshana has a resemblance with lumbosacral plexopathy and sciatic nerve injury Here, marma aghat lakshans can act as predictors of the structures involved. In this study, scholar was trying to nd out exact location of Kukundar Marma and its relationship with other anatomical entities (in circumference of this Marma)

Keywords: Kukunder marma, Ayurveda etc 


\section{INTRODUCTION}

Prishthagata marmas are 14 in number; these are further divided into upper division and lower division by Acharya Ghanekar Marmas of upper division are brihati, amsaphalak and amsa while lower division contains katiktarun, kukundar, nitamb and parshvasandhi marmas. The Marma of lower division are located at gluteal region or within the pelvic cavity, which makes them a dif cult site to approach. Both gluteal region and pelvis acts as a gateway for the passage of major blood vessels and nerves supplying lower limbs and any trauma may result in permanent debility or major life threatening complications. Kukundar Marma is one of the lower division marma which is Vaikalyakara in nature (cause deformity on in iction), situated at Pristha or back of humans on the outer side of Jaghana or pelvic bone, and two in number. Trauma to Kukundar Marma causes loss of sensation and paraparesis which is an indicative of nerve involvement. Depending upon the time and extent of the injury disability caused by this marma can be permanent. Various authors have assumed the probable anatomical position of Kukundar Marma being in between sacroiliac joint and ischial tuberosity. The major nerves related to this area are lumbar and sacral plexus. Most of the Kukundar Marma Aghatjanya Lakshana has a resemblance with lumbosacral plexopathy and sciatic nerve injury. Since sciatic nerve is rather large nerve with multiple root values, therefore the marma can be located anywhere ranging from its root value up to its extent at ischial tuberosity. Mostly trauma caused by a pelvic fracture or acetabular fracture is the major causes of nerve plexopathy at the given area. Lumbosacral plexopathy accounts for $80 \%$ of all nerve injuries after pelvic trauma. Nerve traction sites for the lumbosacral plexus include the dura attachments, connective tissues attachment to the sacral ala and anterior sacroiliac joint. For this reason a detailed anatomic study of sacroiliac joint and associated nerve plexus is done to rule out the location of the marma and all the anatomic structures responsible for its Aghatjanya lakshanas.

Marma sharir is a science of vital anatomical sites which have been established to help the practice of surgery in Ayurveda. Marma are the conglomeration of mamsa, sira, snayu, asthi and sandhi. They are the seats of parana and any injury to them leads to major complications, severe pain or death. Acharya Sushruta has classified these marmas according to the shadang distribution for the purpose of easy understanding their locations, like sakthi gata (limbs), vaksha (thoracic), udar (abdominal), prishtha gata (back) and urdhava jatru gata (above the clavicular level). Prishthagata marmas are 14 in number; these are further divided into upper division and lower division by Acharya Ghanekaz[1] Marmas of upper division are brihati, amsaphalak and amsa while lower division contains katiktarun, kukundar, nitamb and parshvasandhi marmas. The Marma of lower division are located at gluteal region or within the pelvic cavity, which makes them a difficult site to approach. Both gluteal region and pelvis acts as a gateway for the passage of major blood vessels and nerves supplying lower limbs and any trauma may result in permanent debility or major life threatening 
complications. Kukundar Marma is one of the lower division marma which is Vaikalyakara in nature (cause deformity on infliction), situated at Pristha or back of humans on the outer side of Jaghana or pelvic bone, and two in number. Trauma to Kukundar Marma causes loss of sensation and paraparesis which is an indicative of nerve involvement. Depending upon the time and extent of the injury disability caused by this marma can be permanent. Various authors have assumed the probable anatomical position of Kukundar Marma being in between sacroiliac joint and ischial tuberosity. The major nerves related to this area are lumbar and sacral plexus. Most of the Kukundar Marma Aghatjanya Lakshana has a resemblance with lumbosacral plexopathy and sciatic nerve injury. Since sciatic nerve is rather large nerve with multiple root values, therefore the marma can be located anywhere ranging from its root value up to its extent at ischial tuberosity. Mostly trauma caused by a pelvic fracture or acetabular fracture is the major causes of nerve plexopathy at the given area. Lumbosacral plexopathy accounts for $80 \%$ of all nerve injuries after pelvic trauma. [2] Nerve traction sites for the lumbosacral plexus include the dura attachments, connective tissues attachment to the sacral ala and anterior sacroiliac joint. For this reason a detailed anatomic study of sacroiliac joint and associated nerve plexus is done to rule out the location of the marma and all the anatomic structures responsible for its Aghatjanya lakshanas.

Kukundara Word Sabda- Sagar. [3] and Vaman Shivram Apate[4] have described that Kukundara are cavities of loins (the part of the body on both sides of the spine between the lowest ribs and hip bones). Acharya Susruta has described that Kukundara Marma are present in the two flanks, on the outer side of the buttocks on the sides of the vertebral column; and injury to this produce loss of sensation and function of the lower part of the body.[5] Acharya Gayadas has interpreted this marma to be situated at the lateral part of jaghana near the nitamb and are slightly depressed or deep seated; these are ardhaangula in praman and vaikalyakara in nature.

\section{DISCUSSION}

Acharyas have said that Kukundar Marma is located on "Pristhvansaubhyato" (both sides of the spine), and "Parshvajaghanabhirbhage" (dorso-later part of pelvic bone). it is classified under sandhi marma, joint present at the dorsal portion and bilateral to vertebral column is sacroiliac joint. This joint is extended from S1, 2 \& 3 sacral segments and is in close association with lumbosacral trunk. The lumbosacral trunk is the closest anatomical structure to the sacrum passing just $0.1 \mathrm{~mm}$ off of the anterior surface periosteum.[7] Lumbar part of the lumbosacral trunk is formed by 4th and5th lumbar vertebral Rami. [8] It traverses across the sacroiliac joint $2 \mathrm{~cm}$ below the pelvic brim.[9] Lumbosacral trunk is approximately $30 \mathrm{~mm}$ in length. [10] It is main plexus which innervates to lower limb. The L5 nerve root exits inferior to the lumbosacral ligament and is fixed to the anterior superior sacral ala. [1] pelvic rim where it is joined by the $\mathrm{S} 1$ root.[12] Any trauma to sacroiliac joint (fracture or dislocation) will most likely result in an L5 nerve root injury and affliction of lumbosacral plexus resulting in 
lumbosacral plexopathy which accounts for $80 \%$ of all nerve injuries after pelvic trauma. [13] The lumbosacral trunk gives its branches to sciatic nerve $(L 4, L 5, S 1,2,3)$, superior (L4,5-S1) \& inferior gluteal (L5S1,2) nerves, nerve to obturator internus $(L 5-S 1,2)$, nerve to quadratus femoris (L4,5-S1).All these structures emerges from pelvic cavity to supply gluteal surface through sciatic foramen, it is a nearly round hollow cavity present at the dorsum of iliac bone. And kukunder word itself means a round cavity or pit, which states that this marma should be located near a round shaped hollow pit. Injury to kukunder marma results in loss of sensation and movement of lower limb. Lesions of lumbosacral trunk present with foot drop, with variable buttock pain and numbness in the lateral leg and the dorsum of the foot. Neurological findings include not only weakness of ankle and toe dorsiflexion and ankle eversion, but also ankle inversion and toe flexion. There is also variable weakness of the glutei and hamstring muscles. Plantar flexion and ankle jerk usually are normal. Sensory loss is in the L5 dermatomal distribution. Detecting weakness in ankle inversion (tibialis posterior) or toe flexion (flexor digitorum longus), eliminates a peroneal neuropathy. [14] The sacroiliac joint is a complex joint capable of small amount of movement. It has an auricular or Cshaped, $L$ shaped configuration. It has a short cranial (more fibrous) and longer caudal limb (more synovial).[15] It is present on both side of vertebral column and on dorsal aspect of gluteal region, the most closely situated soft tissue element is lumbosacral trunk, which is in close association with the lower part of the joint. Its trauma and leisions produces same effect as described in kukundar marma aghat lakshans. Kukundar marma is ardhangul in praman $(\sim .93 \mathrm{~cm})[16]$ but the average auricular area of $\mathrm{SIJ}$ is $\sim 10.7$ $\mathrm{cm} 2-14.2 \mathrm{~cm} 2$, which is far greater than the marma expansion. But Acharya dalhan has said that this marma is slightly nimna (deep) in its position, so taking his interpretation in consideration up to the depth of $1 \mathrm{~cm}$ from inferior point of sacroiliac joint as well as circumference of the area, which is in close association with greater sciatic foramen (a round cavity) was taken in account for the position of kukundar marma.

\section{REFERENCES}

yurvedarahasyadipika Susruta Samhita Sharir Sthana Patekmarmanirdesh Shariram 6/34, Hindi Commentary by Dr. Ghanekar

B.G.,

Meharchand Lachhmandas publications New Delhi, 2017:196..

Anthony Chiodo, Neurologic injury associated with pelvic Trauma: Radiology and electro diagnosis Evaluation and their Relationships to pain and gait; original article 2007, doi:10.1016/j.apmr.2007.06.004. Shabda Sagar, page no. 184

Vaman Shivram Aapte The Practical Sanskrit English Dictionary, Printed at Arya Vijyaya, Poona, 1890: 280.

Ibidm Sushruta Samhita, Sharir Sthan chapter 6/27,35, p.5

Https:// www.anatomy next .com superior gluteal artery> retrieved on 26/3/2020.

https://www.ncbi.nim.nih.gov >anatomic parameters for instrumentation of the 
sacrum and pelvis: a systematic review of the literature. Retrieved on 6 feb 2020.

Greys Anthony Chiodo, Neurologic injury associated with pelvic trauma: radiology and electro diagnosis evaluation and their relationship to pain and gait outcome, Arch phys med rehab vol 88, September 2007

https://www.sciencedirect.com>electro myography in clinical practice > case 5 . Retrived on $23 / 3 / 2020$.

https://www.ncbi.nlm.nih.gov>the sacroiliac joint an overview... retrieved on

https://www.scholar.google.com Shashikant dadaso Wadkar et.al Lepa treatment in vishachikitsa wsr to brihatrayees- Areview.>Retrived on 3/2/2020.

https://www.ncbi.nlm.nih.gov>the sacroiliac joint an overview... retrieved on

https://www.ncbi.nim.nih.gov >anatomic parametersfor instrumentation of the sacrum and pelvis: a systematic review of the literature. Retrived on 6 feb 2020. 